\title{
How Much Cash Is At Risk In U.S. Non- Financial Firms? A VaR-Type Measurement
}

\author{
Frantz Maurer, KEDGE Business School \& University of Bordeaux - IRGO, France
}

\begin{abstract}
Risk management techniques first developed by, and for, banks are now being adopted by nonfinancial corporations. However, while firms are already engaged in activities intended to develop their risk management practices, they often do not possess risk measures focused on key corporate financial results such as earnings or cash flow. The main contribution of this paper is to develop a cash flow-based risk measure conditional on specific company-level factors. With U.S. firm-level data, we present evidence that Cash Flow-at-Risk and Expected shortfall differ across main nonfinancial industries. Our results call for renewed attention to the role that VaR-type measures for cash flow can play in empirical studies dedicated to corporate risk analysis, and with respect to corporate-level risk management purposes.
\end{abstract}

Keywords: Risk Management; Corporate Risk Analysis; Operating Cash Flow; Var-Type Measurement

\section{INTRODUCTION}

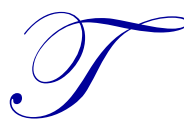

he issue of risk management in non-financial corporations is gaining momentum, and demanding the attention of corporate management, as well as that of financial theorists. Whereas traders, portfolio managers, or treasurers tend to manage the value of their assets and liabilities, corporate managers tend to focus more on the level, growth, and the volatility of corporate financial results such as earnings and cash flow as benchmarks for good performance. In this study, we propose a re-characterization of Value-at-Risk, or VaR, concepts from a financial environment to a cash flow environment.

The idea that the principles of $\mathrm{VaR}$ - which were initially developed for managing risk in a financial environment - can be applied in the corporate environment is not new. The first attempt to create a cash flow equivalent of VaR originates from the Riskmetrics Group within J.P. Morgan in 1999. This company developed a conceptual framework that relies on a measure of downside risk known as Cash Flow-at-risk, or CFaR. This metric enables corporate managers to determine the maximum shortfall of cash the firm is willing to tolerate with a specified confidence level. RiskMetrics' definition of CFaR targets cash flow volatility conditional on market risks arising from a number of factors, including foreign exchange exposures, interest rate exposure, or commodity pricesensitive revenues or expenses. Stein et al. (2001) proposed a comparables-based approach to estimating CFaR. Their approach is based on the assumption that the ultimate variable of interest is the total variability of operating cash flow, and not some conditional version of it. More recently, Andrén et al. (2005) have recommended another approach, called "Exposure-Based CFaR", which can be used to calculate both the firm's overall CFaR and its CFaR conditional on macroeconomic and market risks.

Although both theory and practitioners point to the importance of a corporate analog to VaR-as nonfinancial firms further develop their risk management practices-there is a paucity of prior studies interested in developing a reasonable accurate estimate of CFaR. We aim to fill this research gap by developing a measure of Cash Flow-at-Risk conditional on three specific company-level factors: total assets, capital expenditures, and change in operating working capital. The rationale for such a measure is that individual companies typically have little if any influence on the classic market risks, though some may have informational insights as a result of the nature of their businesses (e.g., commodity and energy companies) that provide them with a comparative advantage to bear certain market risks. By contrast with prior studies, we focus here on two risk measures: Cash Flow-at-Risk and Expected shortfall, conditional on factors that are subject, to a certain extent, to management's control or influence. 
Another contribution of our study is that it provides evidence of the importance of specific company-level factors in explaining the cross-sectional variation of cash from operations and hence Cash Flow-at-Risk. Specifically, our dataset is constructed using U.S. firm-level data from nine major industries-Oil \& gas, Basic Materials, Industrials, Consumer Goods, Healthcare, Consumer services, Telecommunications, Utilities, and Technology-over the 2000-2009 period. Using such data is a departure from prior CFaR studies that focus on a single Norwegian industrial conglomerate (Andrén et al., 2005), or aggregate data for a large number of companies, regardless of the industry in which they operate (Stein et al., 2001). The data used in this study allow us to conduct a more robust and detailed analysis of Cash Flow-at-Risk and help enhance our understanding of the corporate forces that affect it. In this respect, our empirical results call for reinforced attention to the under-researched question of risk measurement in the corporate environment.

The organization of this paper is as follows. The next section investigates the link between Cash Flow-atRisk and risk management theories. Section 3 explains the method used for calculating Cash Flow-at-Risk. Section 4 describes the data. Section 5 conducts an empirical analysis and presents the results. Section 6 concludes the paper.

\section{RISK MANAGEMENT THEORIES AND CASH FLOW-AT-RISK}

The traditional approach to explaining why companies would want to manage risk in the first place is to claim that managers act in order to reduce the probability of default and to reduce the cost of financial distress (Smith and Stulz, 1985). The argument arises out of a market imperfection in that financial distress can be costly. More recent research in corporate finance has shown that greater volatility of cash flow increases the present value of deadweight costs of financial distress (Froot et al., 1993; Minton and Schrand, 1999). As pointed out by Stein et al. (2001), the volatility of cash flow is perhaps the most significant determinant of the probability of financial distress - hence the usefulness of CFaR. A related argument is that risk management increases corporate debt capacity. By implementing an effective corporate risk management program that aims to reduce the risk of insufficient cash flow and financial distress, companies can ensure access to capital and potentially optimize their capital structure by expanding their debt capacity, thereby increasing the tax benefits of debt financing. CFaR can help formulate debt-equity tradeoffs in a more quantifiable fashion.

Another line of argument in favor of risk management is that it can be an important tool for creating shareholder value. The idea is that companies can create value by establishing a risk management program that ensures they have sufficient funds or access to capital to keep value-enhancing projects on-line (Servaes et al., 2009). Stulz (1996) proposes a model according to which the company should eliminate "costly lower-tail outcomes" through risk management, that is, limiting its downside risk while preserving its ability to exploit profitable opportunities in relation to its comparative advantages and its private information. Beyond this wellknown underinvestment problem, corporate risk management can add value by identifying the risk associated with alternate business decisions and thus helping a firm attain what it believes to be its appropriate risk profile. However, to assess to what extent the firm should target its risk, the manager must first understand the channels through which risk management can potentially affect firm value (Meulbroek, 2002). In this aim, one again needs to have a reliable $\mathrm{CFaR}$ estimate.

An important argument in favor of risk management is that it promotes greater transparency. Risk management disclosure can help analysts, rating agencies, and shareholders gain comfort with a company's risk management approach and make more informed assessments about future cash flow volatility. Risk management can also help investors, the board of directors, or senior management identify the underlying profitability of a business and distinguish superior operating performance from favorable moves in market variables such as commodity prices and FX (DeMarzo and Duffie, 1991). Within the company, a risk management framework can be used to assess the appropriateness of the company's risk profile. By disclosing the results of a CFaR analysis, corporate managers can improve communication about risk both internally and externally.

While less developed, in theory, there are other reasons in favor of risk management. For example, Servaes et al. (2009), in their global survey of over 300 CFOs of non-financial companies, report that the most valuable benefit of risk management is to improve risk-based decision making throughout the company. Surprisingly, senior finance executives acknowledge that risk-based thinking is not incorporated into everyday business activities or 
corporate strategies. The authors interpret this as a strong desire for risk management programs to instill a risk culture in the company. They also indicate that risk management can preserve the company's reputation. What is important to keep in mind is that risk management is not only a decision about how much risk the company should bear, it is also a decision about how much risk the company's customers or suppliers are prepared to bear (Meulbroek, 2002). To the extent risk management succeeds in increasing the stability of cash flow, it strengthens the firm's reputation with investors and other stakeholders. Using CFaR, a firm can communicate an "official" understanding of risk throughout the company, and thus improve the clarity of risk awareness.

\section{METHOD FOR CALCULATING CASH FLOW-AT-RISK}

\subsection{Cash Flow Definition}

We use operating cash flows to measure the cash flow of a non-financial company ${ }^{1}$. The literature employs several alternative definitions of cash flow. For example, Bates et al. (2009) measure cash flow as earnings after interest, dividends, and taxes but before depreciation divided by book assets. Brown and Petersen (2010) use a gross cash flow measure defined as after-tax income before extraordinary items plus depreciation and amortization plus research and development expense.

Our primary reason for selecting the operating cash flow is that corporate managers are interested in the exposures of corporate cash flow measures such as operating cash flow for reasons of corporate planning and risk management (Bartram, 2007). In particular, using a proprietary set of detailed internal cash flow data, Bartram (2008) documents a significant exposure of the operating cash flows to the exchange rates that are of key relevance for the business activities of a large multinational firm. Most importantly, the results from the survey conducted by Servaes et al. (2009) indicate that CFOs focus primarily on operating cash flows in their risk management program.

Although the cash flow variables included in regression models are typically calculated as the change in the level of cash flow from year $t$-1 to year $t$, we focus on regressions using raw operating cash flow levels to create the dependent variables. As argued by Andrén et al. (2005), exposure can be estimated using data expressed as levels, first differences, or percentage changes. From an informational point of view, the choice is irrelevant because the information in one dimension can easily be expressed in terms of another. Using changes in the cash flow variables rather than levels does not affect our results in a material way. It should be noted that we did not use scaling procedures, such as normalizing the operating cash flow with the contemporary total sales, total assets or net total assets (total assets minus cash), because total assets is included in the cash flow regressions as an explanatory variable.

\subsection{Multivariate Regression Model}

We consider three main specific company-level effects or factors- the total assets, the capital expenditures and the change in operating working capital - to explain the specific component of operating cash flow. A multivariate regression is performed to estimate the magnitudes of these influential factors. The coefficients produced by such a regression provide the basis for a CFaR calculation. The general linear static model is specified as follows:

$$
y_{i t}=\alpha_{i t}+\beta_{i t}^{\prime} x_{i t}+\varepsilon_{i t}, \quad \begin{aligned}
i & =1, . ., N, \\
t & =1, . ., T,
\end{aligned}
$$

where $y_{i t}$ denotes the cash flow from operations of firm $i$ at time $t, \alpha_{i t}$ and $\beta_{i t}^{\prime}=\left(\beta_{l i t}, \beta_{2 i t}, \beta_{3 i t}\right)$ are $1 \times 1$ and $1 \times 3$ vectors of constants, respectively, $x_{i t}^{\prime}=\left(x_{l i t}, x_{2 i t}, x_{3 i t}\right)$ is a $1 \times 3$ vector of exogenous variables denoting the total assets,

\footnotetext{
${ }^{1}$ The operating cash flow captures cash received by the company from its everyday business operations. The number does not include cash from other sources such as investments. It is important for a company to have positive operating cash flow as this shows at least short-term viability. 
the capital expenditures, and the change in operating working capital of firm $i$ at time $t$, respectively, and $\varepsilon_{i, t}$ is the error term with mean zero and constant variance $\sigma_{\varepsilon}^{2}$.

\subsection{Monte Carlo simulating procedure}

Calculating the $\mathrm{CFaR}$ requires first to build the probability distribution of operating cash flows. In this aim, we use a simulation-based approach to generating a large number of scenarios that chart the different possible values for the aforementioned specific company-level factors. The advantage of this approach is the ability to describe in detail a distribution of financial results, from which a variety of risk measures may be obtained. As risk measures, we select the CFaR and the Expected Shortfall, both of which are widely used. In the Monte Carlo simulating procedures, the stochastic processes of the specific company-level factors are assumed to follow a generalized Brownian motion such as follows:

$x_{k i t}=\mu_{k i t}+\sigma_{k i t} \varepsilon_{k i t}, \quad k=1, \ldots, 3$

where, for the firm $i$ at time $t$ :

$x_{k i t}$ is the value of the specific company-level factor $k$,

$\mu_{k i t}$ is the expected value of the specific company-level factor $k$,

$\sigma_{k i t}$ is the standard deviation of the specific company-level factor $k$,

$\varepsilon_{k i t}$ is the noise of the specific company-level factor $k$ at time $t$.

The noise $\varepsilon_{k i t}$ in [2] is assumed to follow a standard normal distribution.

A common hypothesis regarding error terms $\varepsilon_{k i t}$ in [2] is to assume that they are mutually independent when the $\mathrm{CFaR}$ is calculated. However, the resulting CFaR may be not reliable because the specific company-level factors may be correlated with each other. To account for this correlation and hence generate a more accurate picture of the probability distribution of cash flows, we use the Cholesky factorization such as described in what follows. The matrix of correlations between the three specific company-level factors, denoted $\Omega$, is defined as follows:

$\Omega=\left(\begin{array}{ccc}1 & & \\ \rho_{2,1} & 1 & \\ \rho_{3,1} & \rho_{3,2} & 1\end{array}\right)$

where $\rho_{i, j}$ denotes the correlation between the company-level factors $i$ and $j$.

As the matrix $\Omega$ is a symmetric real matrix, it can be decomposed into its Cholesky factors $\Omega=L L^{\prime}$, where $L$ is a lower triangular matrix with zeros on the upper right corners, such as:

$$
\left(\begin{array}{ccc}
1 & 0 & 0 \\
\rho_{2,1} & \sqrt{1-\rho_{2,1}} & 0 \\
\rho_{3,1} & \frac{\rho_{3,2}-\rho_{3,1} \rho_{2,1}}{\sqrt{1-\rho_{2,1}^{2}}} & \sqrt{1-\rho_{3,1}^{2}-\frac{\left(\rho_{3,2}-\rho_{3,1} \rho_{2,1}\right)^{2}}{1-\rho_{2,1}^{2}}}
\end{array}\right)
$$


Then, we define a $1 \times 3$ vector $\eta_{k i t}^{\prime}=\left(\eta_{1 i t}, \eta_{2 i t}, \eta_{3 i t}\right)$ that is composed of independent random variables following a standard normal distribution, and where $k=1, . ., 3$ denotes the three specific company-level factors: total assets, capital expenditures, and change in operating working capital. Next, using [4], we construct the specific companylevel innovation $\varepsilon_{k i t}=L \eta_{k i t}$, where $\varepsilon_{k i t}^{\prime}=\left(\varepsilon_{1 i t}, \varepsilon_{2 i t}, \varepsilon_{3 i t}\right)$. In so doing, we confirm that the values of $\varepsilon_{k i t}$ display the desired correlation structure between the specific company-level factors. We then use Monte Carlo methods to simulate 10,000 operating cash flow scenarios conditional on the three specific company-level factors. From the resulting probability distribution of simulated cash flows, we compute two risk statistics: Cash Flow-at-Risk and Expected shortfall.

The procedure for measuring corporate risk is based on equations [1], [2] and [4]. It can be summarized in five basic steps ${ }^{2}$ :

Step 1: Estimate the vector of means and the variance-covariance matrix of the specific company-level factors.

Step 2: Simulate 10,000 values of the specific company-level factor innovations through the equation: $\varepsilon_{k i t}=L \eta_{k i t}$, with $L$ given by [4].

Step 3: From the innovations simulated in step 2, compute 10,000 values of each specific company-level factor defined by [2].

Step 4: Based on the estimated magnitudes of the specific company-level factors (output from the multivariate regression), compute 10,000 scenarios of operating cash flows by inserting the values obtained in step 3 in [1].

Step 5: From the probability distribution of cash flows built in step 4, calculate the CFaR and Expected Shortfall risk statistics for a specified confidence level.

\subsection{Risk Measures Specification}

We use in this paper two quantile-based measures of risk: Cash Flow-at-Risk and Expected Shortfall. Both are derived from the well-known "variance-quantile" method of Value-at-Risk (VaR) widely used within financial institutions. In essence, $\mathrm{CFaR}$, like $\mathrm{VaR}$, asks the simple question all senior managers want answered: "How bad can things get?"

One disadvantage of both $\mathrm{VaR}$ and $\mathrm{CFaR}$ is that they do not give an indication of the magnitude of the potential losses in the tail or by how much any actual losses will exceed the VaR or CFaR figure. Artzner et al. (1999) have recommended an alternative risk measure that tackles the question of "how bad is bad", which is not addressed by the VaR or CFaR measurement. This measure is referred to as "expected shortfall", "conditional VaR" or "Tail Conditional Expectation". Whereas CFaR asks how bad things can get, expected shortfall asks: "If things do get bad, what is the expected loss?" It should be noted that expected shortfall has better theoretical properties than the traditional CFaR. Specifically, Artzner and his co-authors demonstrated that expected shortfall satisfies all requirements for a so-called coherent measure of risk ${ }^{3}$.

Let consider a cash flow random variable $X$. Following Artzner et al. (1999), we formally define CFaR and expected shortfall in the following way:

\footnotetext{
${ }^{2}$ This five-step process can be easily modified to derive a probability distribution of unconditional cash flows or independent of specific company-level factors. In step 1, compute the mean and standard deviation of the residuals from regression [1]. In step 2, simulate 10,000 values of the firm-independent innovation (the error term in equation [1]). The CFaR is then calculated as the quantile at the $\alpha$ significance level of the unconditional cash flows probability distribution. Note that the conditional and unconditional risk components should not be viewed as additive, or summing to a whole to get a so-called total $\mathrm{CFaR}$, since the firm-independent innovation in equation [1] is defined to be independent of specific company-level factors. This holds true for the calculation of an unconditional Expected Shortfall.

${ }^{3}$ Artzner et al. (1999) have proposed four properties that a risk measure should have: Monotonicity, translation invariance, homogeneity, and subadditivity. Risk measures satisfying all four conditions are referred to as coherent. While satisfying the first three properties, CFaR violates the subadditivity property, as opposed to the expected shortfall.
} 
CFaR measurement: given $\alpha \in$ ]0, 1[, the Cash Flow-at-Risk $\mathrm{CFaR}_{a}$ at level $\alpha$ of the final net worth $X$ with distribution $P$, is the negative of the quantile $q_{\alpha}^{+}$of $X$, that is

$$
\operatorname{CFaR}_{\alpha}(X)=-\inf \{x \mid P[X \leq x]>\alpha\} .
$$

Put simply, [5] denotes the maximum loss such that the probability of incurring any higher loss is set in advance at level $\alpha$.

Expected shortfall measurement: given a base probability measure $P$ and a level $\alpha$, the expected shortfall $\mathrm{ES}_{a}$ is the measure of risk defined by

$$
E S_{\alpha}(X)=-E_{P}\left[X \mid X \leq-C F a R_{\alpha}(X)\right] .
$$

Put simply, [6] denotes the expected loss conditional on the loss being greater than the CFaR level or the expected worse cash flow that can potentially be experienced. Therefore, when compared to the CFaR measure in [5], the Expected shortfall in [6] provides a more conservative measure of risk for the same level of degree of confidence ${ }^{4}$. Both risk measures in [5] and [6] are supposed to provide a value for the degree of risk or uncertainty associated with the cash flow random variable $X$.

\section{DATA}

The source of our data is the Corporate Focus Premium Infinancials database. The sample period covers the 2000-2009 period. In constructing our sample, we collect data for every firm included in the database 5 . We discard firms in the financial industry. We require that firms have positive values for the book value of total assets to be included in a given year. Finally, we restrict our sample to firms that are incorporated in the Unites States.

The sample is comprised of nine major sectors-Oil \& gas, Basic Materials, Industrials, Consumer Goods, Healthcare, Consumer services, Telecommunications, Utilities, and Technology. This industry structure follows the Industry Classification Benchmark ${ }^{6}$.Our analysis is conducted separately for each industry. Data requirements limit the size of our sample. For example, the unrestricted Consumer services subsample has 628 firms, but only 578 firms have sufficient data to estimate regressions [1], as indicated in Table 1.

To cope with extreme values in our raw data, we winsorized the operating cash flow variable at the top one percent of its distribution. The key variables we use as determinants of operating cash flow also pose outlier problems. To address these problems, outliers in all regression variables are trimmed at the $1 \%$ level. Table 1 provides summary statistics for the operating cash flow variable as well as key variables for each of the nine industries in our sample.

This table presents summary statistics on operating cash flows and key variables for nine industries for the period 2000-2009. The measure of cash flow from operations is CFO. The three key variables are: (i) TA, total assets, (ii) CAPEX, capital expenditures, and (iii) $\triangle \mathrm{OWC}$, change in operating working capital. The table reports mean and standard deviation (in parentheses) values for these variables. $N$ is the number of observations and $n$ is the number of firms. Display Currency: USD (in millions).

\footnotetext{
${ }^{4}$ For a straightforward proof of this result, see Landsman and Valdez (2003), p. 56.

${ }^{5}$ Note that the Infinancials database includes only quoted firms.

${ }^{6}$ The Industry Classification Benchmark was created by Dow Jones Indexes and Ftse. The nature of a company's business is determined by its source of revenue or where it constitutes the majority of revenue.
} 
Table 1. Summary statistics

\begin{tabular}{|c|c|c|c|c|c|c|}
\hline Industry & $N$ & $n$ & CFO & TA & CAPEX & $\Delta O W C$ \\
\hline Oil \& gas & 1728 & 296 & & & & \\
\hline $\begin{array}{l}\text { Mean } \\
\text { (St. dev.) }\end{array}$ & & & $\begin{array}{c}654.34 \\
(3466.56)\end{array}$ & $\begin{array}{c}4454.83 \\
(19015.57)\end{array}$ & $\begin{array}{l}-500.06 \\
(181.98)\end{array}$ & $\begin{array}{l}-159.92 \\
(237.24)\end{array}$ \\
\hline Basic materials & 1127 & 194 & & & & \\
\hline $\begin{array}{l}\text { Mean } \\
\text { (St. dev.) }\end{array}$ & & & $\begin{array}{r}193.90 \\
(525.04) \\
\end{array}$ & $\begin{array}{r}2388.53 \\
(6114.96) \\
\end{array}$ & $\begin{array}{l}-136.05 \\
(351.30) \\
\end{array}$ & $\begin{array}{l}-197.53 \\
(187.11) \\
\end{array}$ \\
\hline Industrials & 4875 & 813 & & & & \\
\hline $\begin{array}{l}\text { Mean } \\
\text { (St. dev.) }\end{array}$ & & & $\begin{array}{r}241.68 \\
(1734.82) \\
\end{array}$ & $\begin{array}{c}3639.11 \\
(35545.91) \\
\end{array}$ & $\begin{array}{l}-102.12 \\
(711.66) \\
\end{array}$ & $\begin{array}{r}502.81 \\
(468.80) \\
\end{array}$ \\
\hline Consumer goods & 2463 & 408 & & & & \\
\hline $\begin{array}{l}\text { Mean } \\
\text { (St. dev.) }\end{array}$ & & & $\begin{array}{c}293.91 \\
(1337.23) \\
\end{array}$ & $\begin{array}{r}3906.75 \\
(22137.62) \\
\end{array}$ & $\begin{array}{l}-981.37 \\
(425.29) \\
\end{array}$ & $\begin{array}{l}-309.52 \\
(327.83) \\
\end{array}$ \\
\hline Healthcare & 4060 & 673 & & & & \\
\hline $\begin{array}{l}\text { Mean } \\
\text { (St. dev.) }\end{array}$ & & & $\begin{array}{c}167.92 \\
(1057.46)\end{array}$ & $\begin{array}{c}1562.25 \\
(8349.53)\end{array}$ & $\begin{array}{l}-405.53 \\
(188.43) \\
\end{array}$ & $\begin{array}{l}-590.41 \\
(280.09) \\
\end{array}$ \\
\hline Consumer services & 3610 & 578 & & & & \\
\hline $\begin{array}{l}\text { Mean } \\
\text { (St. dev.) } \\
\end{array}$ & & & $\begin{array}{r}286.47 \\
(931.29) \\
\end{array}$ & $\begin{array}{r}3228.86 \\
(10725.16) \\
\end{array}$ & $\begin{array}{l}-183.68 \\
(734.88) \\
\end{array}$ & $\begin{array}{l}-218.99 \\
(570.30) \\
\end{array}$ \\
\hline Telecommunications & 371 & 59 & & & & \\
\hline $\begin{array}{l}\text { Mean } \\
\text { (St. dev.) }\end{array}$ & & & $\begin{array}{c}1268.05 \\
(4840.96)\end{array}$ & $\begin{array}{c}11105.38 \\
(39564.56)\end{array}$ & $\begin{array}{l}-746.11 \\
(290.17)\end{array}$ & $\begin{array}{l}-740.86 \\
(518.05)\end{array}$ \\
\hline Utilities & 510 & 109 & & & & \\
\hline $\begin{array}{l}\text { Mean } \\
\text { (St. dev.) }\end{array}$ & & & $\begin{array}{c}641.55 \\
(926.78) \\
\end{array}$ & $\begin{array}{c}10142.89 \\
(12741.04)\end{array}$ & $\begin{array}{l}-594.50 \\
(817.22)\end{array}$ & $\begin{array}{l}-375.53 \\
(304.32)\end{array}$ \\
\hline Technology & 4046 & 655 & & & & \\
\hline $\begin{array}{l}\text { Mean } \\
\text { (St. dev.) }\end{array}$ & & & $\begin{array}{c}225.38 \\
(1341.61)\end{array}$ & $\begin{array}{c}1620.59 \\
(7776.02)\end{array}$ & $\begin{array}{l}-646.75 \\
(362.83)\end{array}$ & $\begin{array}{r}415.60 \\
(168.82)\end{array}$ \\
\hline
\end{tabular}

\section{EMPIRICAL RESULTS}

\subsection{Multiple Regressions on Operating Cash Flows}

We estimate the linear static regression model, defined by [1], to examine the simultaneous impact of the three key factors on operating cash flows. Some empirical studies include control variables in such regressions. In a study evaluating the impact of cash-flow uncertainty on dividends, Chay and Suh (2009) use firm size measured by the logarithm of total assets, operating profitability measured by operating income scaled by total assets, and cash holdings measured by cash plus short-term investments scaled by total assets. They estimate a regression model without the control variables and find qualitatively similar results, with respect to the importance of the key determinants of payout policy. As mentioned before, we select total assets as a potential influential factor of operating cash flow. As a result, this item cannot be used neither to scale any variables included in regressions nor as a control variable because of endogeneity.

One can argue that in case of large samples, a control variable measuring firm size is required. Nevertheless, Bartram (2007) estimates the foreign exchange rate exposure of 6917 U.S. nonfinancial firms on the basis of stock prices and corporate cash flows, without including control variables in his regression models, and finds significant results. In another related study, Bartram (2008) includes different sets of macroeconomic variables in his regressions as control variables in order to verify the robustness of the results, and concludes that the main results are unchanged. Overall, there is no reason to believe that not including control variables in equation [1] will bias our results. 
Two aspects of the estimated regression coefficients in the unrestricted model defined by [1] can be tested: first, the homogeneity of the regression slope coefficients; second, the homogeneity of regression intercept coefficients. In this aim, we use the 3 -step analysis-of-covariance test procedure developed by Hsiao $(1986)^{7}$ :

1. Test for overall homogeneity (slopes and intercepts simultaneously are homogeneous among different firms at different times).

2. Test for slope homogeneity (the regression slopes collectively are the same).

3. Test for homogenous intercept conditional on acceptance of homogenous slopes (the final test to determine the equality of regression intercepts).

Ignoring parameter heterogeneity among cross-sectional units in a panel data set can lead to inconsistent or meaningless estimates of interesting parameters (Greene, 2008). For example, our unrestricted model, as expressed by [1], can be estimated through a pooled regression if and only if the hypothesis of overall homogeneity $\mathrm{H}_{1}$ in step 1 is accepted. If not, the pooled least-squares estimates may lead to false inferences.

Following the test sequence described above, one can use a $F$-test for overall homogeneity $\left(\mathrm{H}_{1}\right.$ in step 1$)$, slope homogeneity $\left(\mathrm{H}_{2}\right.$ in step 2$)$, and intercept homogeneity conditional on acceptance of homogenous slopes $\left(\mathrm{H}_{3}\right.$ in step 3), respectively. The results for testing homogeneity of time-series estimates across cross-sectional units (firms) are reproduced in Table 2. These results allow discriminating between the pooled regression and the specific effects (as fixed or random) model and the associated estimation methods.

Table 2 presents covariance tests for regression coefficient homogeneity across cross-sectional units. The table reports the actual and critical $F$ values for each step of the analysis-of-covariance test procedure developed by Hsiao (1986). $\mathrm{F}_{1}, \mathrm{~F}_{2}$, and $\mathrm{F}_{3}$ denote the $F$ statistics used to test $\mathrm{H}_{1}$ (overall homogeneity), $\mathrm{H}_{2}$ (slope homogeneity), and $\mathrm{H}_{3}$ (intercept homogeneity conditional on acceptance of homogenous slopes), respectively. All critical values are computed for the $95 \%$ significance level.

Table 2. Covariance Tests for Homogeneity ${ }^{\mathrm{a}}$

\begin{tabular}{|c|c|c|c|c|}
\hline Industry & $\begin{array}{c}\text { Actual } F \\
(\text { Critical F })\end{array}$ & $\begin{array}{c}\text { Actual } F \\
(\text { Critical F })\end{array}$ & $\begin{array}{c}\text { Actual } F \\
(\text { Critical F })\end{array}$ & Model structure \\
\hline Oil \& gas & $\begin{array}{c}.83 \\
(1.12) \\
\end{array}$ & & & Pooled regression \\
\hline Basic materials & $\begin{array}{c}1.16 \\
(1.66)\end{array}$ & & & Pooled regression \\
\hline Industrials & $\begin{array}{l}3.65 \\
(1.07) \\
\end{array}$ & $\begin{array}{c}1.07 \\
(2.45)\end{array}$ & $\begin{array}{c}3.86 \\
(1.08)\end{array}$ & Specific effects model \\
\hline Consumer goods & $\begin{array}{c}9.79 \\
(1.10) \\
\end{array}$ & $\begin{array}{c}1.11 \\
(1.44)\end{array}$ & $\begin{array}{l}27.61 \\
(1.12)\end{array}$ & Specific effects model \\
\hline Healthcare & $\begin{array}{c}5.95 \\
(1.08) \\
\end{array}$ & $\begin{array}{c}1.08 \\
(1.18) \\
\end{array}$ & $\begin{array}{l}18.26 \\
(1.09)\end{array}$ & Specific effects model \\
\hline Consumer services & $\begin{array}{c}6.10 \\
(1.08) \\
\end{array}$ & $\begin{array}{c}1.08 \\
(3.03)\end{array}$ & $\begin{array}{c}7.08 \\
(1.10) \\
\end{array}$ & Specific effects model \\
\hline Telecommunications & $\begin{array}{c}8.64 \\
(1.29)\end{array}$ & $\begin{array}{c}1.31 \\
(5.78)\end{array}$ & $\begin{array}{c}4.67 \\
(1.34)\end{array}$ & Specific effects model \\
\hline Utilities & $\begin{array}{c}1.97 \\
(1.36)\end{array}$ & $\begin{array}{c}1.14 \\
(1.37)\end{array}$ & $\begin{array}{c}3.99 \\
(1.25)\end{array}$ & Specific effects model \\
\hline Technology & $\begin{array}{c}4.47 \\
(1.08) \\
\end{array}$ & $\begin{array}{c}.88 \\
(1.08) \\
\end{array}$ & $\begin{array}{l}16.34 \\
(1.09)\end{array}$ & Specific effects model \\
\hline
\end{tabular}

${ }^{\mathrm{a}}$ If the hypothesis of overall homogeneity $\mathrm{H}_{1}$ is not rejected the testing procedure will go no further.

\footnotetext{
${ }^{7}$ The underlying logic of the Hsiao's 3-step test procedure is the following: if the hypothesis of overall homogeneity $\left(\mathrm{H}_{1}\right.$ in step 1$)$ is accepted, the testing procedure will go no further. If overall homogeneity hypothesis is rejected, a further attempt is made to find out if the nonhomogeneity can be attributed to heterogeneous slopes or heterogeneous intercepts. The hypothesis of heterogeneous intercepts but homogeneous slopes $\left(\mathrm{H}_{2}\right)$ is tested in step 2. If slope homogeneity hypothesis is rejected, the test sequence is naturally halted (a separate regression for each individual must be estimated). If $\mathrm{H}_{2}$ is accepted, a conditional test for homogeneous intercepts is applied in the third and last step.
} 
A striking fact recorded from the statistics displayed in Table 2 is that except for two industries (Oil \& Gas and Basic materials), all others failed the overall homogeneity test. These results imply that individual-specific effects are present in our data set. To decide whether to use a fixed-effects or random-effects model, we use the specification test devised by Hausman (1978). The results are reproduced in Table 3. The evidence is strongly in favor of individual-specific fixed effects. The null hypothesis of the random effects model is always rejected except for the Consumer Goods industry. At this point, we conclude that the fixed effects model is the preferred specification except for the Consumer Goods industry.

In Table 3, the Hausman test is used to test for orthogonality of the common effects and the regressors. Under the null hypothesis of no correlation, $\mathrm{H}_{0}: \mathrm{E}\left(\alpha_{i} \mid \mathrm{X}_{i}\right)=0$, the test statistic is distributed asymptotically as central chi-square, with $K$ degrees of freedom. If the null hypothesis holds, we use the random-effects model. If the alternative hypothesis, $\mathrm{H}_{1}: \mathrm{E}\left(\alpha_{i} \mid \mathrm{X}_{i}\right) \neq 0$, holds, we use the fixed-effects model.

Table 3. Hausman test for fixed versus random effects

\begin{tabular}{llcc}
\hline \multicolumn{1}{c}{ Industry } & Chi-Sq. Statistic & $\boldsymbol{p}$-value & Specific effects model \\
\hline Industrials & Chi2(3) $=188.80$ & 0.0000 & Fixed effects \\
Consumer goods & Chi2 $(3)=8.39$ & 0.1364 & Random effects \\
Healthcare & Chi2 $(3)=3995.33$ & 0.0000 & Fixed effects \\
Consumer services & Chi2 $(3)=144.72$ & 0.0000 & Fixed effects \\
Telecommunications & Chi2 $(3)=153.04$ & 0.0000 & Fixed effects \\
Utilities & Chi2 $(3)=44.02$ & 0.0000 & Fixed effects \\
Technology & Chi2 $(3)=61.70$ & 0.0000 & Fixed effects \\
\hline
\end{tabular}

Based on results from Tables 2 and 3, the general model as defined by [1] is estimated using an OLS regression for the two pooled models (Oil \& Gas and Basic materials), a GLS regression for the random effects model (Consumer goods), and a least squares dummy variable (LSDV) regression for the six fixed effects models. Table 4 shows the results of the regression analysis. Our standard errors allow for clustering by firm, using the procedure in Stock and Watson (2008), and are robust to panel-level heteroskedasticity and autocorrelation ${ }^{8}$. The time-series properties of our panel datasets should not be an important consideration because they contain a fixed and small $T$ observations on a large $n$ individuals units (Greene, 2008, p. 243). However, we use the Im-PesaranShin (2003) test for unit roots in unbalanced panels (not reported). We find strong evidence against the null hypothesis of a unit root and, therefore, conclude that all series are stationary. We also perform the Kwitkowski et al. (1992) (KPSS) unit root test for the Oil \& Gas and Basic Materials series (not reported), and fail to reject the null hypothesis of stationarity at conventional significance levels.

The regression coefficients displayed in Table 4 provide the estimated magnitude of corporate-level factors - defined as total assets, capital expenditures, and change in operating working capital - on cash flow from operations. These estimates are then used as inputs to the Monte Carlo simulation procedure in order to derive both Cash Flow-at-Risk and Expected shortfall. While our regression specification [1] is ad hoc in that it does not specify a functional form that results directly from a theoretical model, it explains a substantial amount of the crosssectional variation in firm operating cash flows. This approach is due to the lack of empirical investigations in the literature, examining the relationship between cash flow and explanatory variables such as those used in this study.

With no exception across nine industries, the sign of the TA coefficient in Table 4 is significant and positive. Also note that the impact of TA on operating cash flow appears to be as great as or greater than the impact of the other variables. This result provides further evidence that total assets are a key factor that explains the crosssection variation of cash from operations. Somewhat surprisingly, however, our results suggest (with the exception of Technology) that operating cash flow is affected negatively by CAPEX. We would expect the opposite pattern because capital expenditures are likely to generate assets that can be used to generate cash. A plausible interpretation is that capital expenditures create assets that can be used as collateral and hence are easier to finance (Bates et al.,

${ }^{8}$ Panel-level heteroskedasticity is checked using a Breusch-Pagan LM test and a modified Wald test for groupwise heteroskedasticity, and panellevel autocorrelation using the test derived by Wooldridge (2002, p. 282-283). According to the results (not reported), we specify heteroskedastic error structure with or without AR(1) autocorrelation. Regarding the pooled regressions, we use the Newey and West's covariance estimator that is consistent in the presence of both heteroskedasticity and autocorrelation of unknown form (see Greene, 2008, p. 643). 
2009). As a result, capital expenditures may mostly consume cash, which would be consistent with a negative relation with cash. It should be noted, however, that such a negative relation is observed when the cash ratio-defined as the ratio of cash and marketable securities to the book value of total assets-is used in regressions, leading to a less counterintuitive result than ours. Finally, the last key factor, $\triangle \mathrm{OWC}$, does not seem to fare well as a cross-sectional determinant of cash from operations. Compared to TA whose impact on operating cash flow is strong across industries, the impact of $\triangle \mathrm{OWC}$ on operating cash flow appears relatively weak. Note that when the associated coefficient is not statistically significant (Telecommunications and Utilities), it is not included in the five-step simulation process used to compute Cash Flow-at-Risk and Expected shortfall.

\subsection{Industry-Level Risk Analysis}

Based on the regression results, we now calculate Cash Flow-at-Risk and Expected shortfall for each industry according to equations [5] and [6], respectively. Table 5 reports the results at the $99 \%$ confidence level. Results show that three distinct groups can be roughly identified. The first one includes the riskiest industries: Utilities, Telecommunications, and Oil \& Gas, with a CFaR at 99\% confidence above 700 millions of dollars. The second group is composed of industries with the lowest risk: Consumer Goods, Technology, and Healthcare, with a $\mathrm{CFaR}$ below 100 millions of dollars. The last group is somewhat difficult to interpret in terms of level of risk. Two industries (Basic Materials and Industrials) exhibit a CFaR ranging between USD400 and USD500 million, and the Consumer services industry displays a CFaR equal to USD162 million. Thus, it might not be very relevant to group together these three sectors. Clearly, Basic Materials and Industrials belong to the same class of risk. However, it seems not meaningful to state that they are of medium risk because they are closer to the first group of very risky industries than the second one. The case of Consumer services is even more complicated. Its CFaR is both too close to the group of the least risky industries and too far from the group of the riskiest industries to be considered as a medium risk class. Expected shortfalls displayed in Table 5 lead exactly to the same conclusions, since they provide a more conservative measure of risk than $\mathrm{CFaR}$ for the same level of confidence.

Table 4 reports regression results on operating cash flows over the period 2000-2009. The dependent variable is the cash flow from operations. The explanatory variables are: (i) TA, total assets, (ii) CAPEX, capital expenditures, and (iii) $\triangle \mathrm{OWC}$, change in operating working capital. Regressions are estimated according to results in tables 2 and 3 . The table reports regression coefficients.

Table 5 presents the computed Cash flow-at-Risk (CFaR) and Expected Shortfall (ES) through the Monte Carlo simulation method. Both are conditional on three specific company-level factors: total assets, capital expenditures, and the change in operating working capital. The mean of operating cash flow is reported from Table 1. Display Currency: USD (in millions). 
Table 4. Regressions to explain operating cash flows ${ }^{\mathrm{a}}$

\begin{tabular}{l|ccc|cc|c|c|c}
\hline \multicolumn{10}{c|}{ Table 4. Regressions to explain operating cash flows } \\
\hline
\end{tabular}

${ }^{a}$ Both variance inflation factors and condition indices indicate that regression results are not affected by a potential multicollinearity problem. The two diagnostics

have values in the range of 1.17-3.56 and 1.32-4.21, respectively, indicating low correlations between all exogenous variables.

Note: Standard errors in parentheses allow for clustering by firm and are robust to heteroskedasticity and autocorrelation. ${ }^{* * *}$ and ${ }^{* * *}$ indicate significance at the $10 \%, 5 \%$, and $1 \%$ levels, respectively. $N$ is the total number of observations and $n$ is the number of firms.

Table 5. Cash Flow-at-Risk, Expected shortfall, and relative CFaR

\begin{tabular}{|c|c|c|c|c|c|}
\hline Industry & CFaR at $99 \%$ confidence & ES at $99 \%$ confidence & $\begin{array}{c}\text { CFaR at } 95 \% \text { confidence } \\
{[\mathrm{A}]}\end{array}$ & $\begin{array}{c}\text { Operating cash flow Mean } \\
{[\mathrm{B}]}\end{array}$ & $\begin{array}{c}\text { Relative CFaR at 95\% confidence } \\
{[[B]-[A]}\end{array}$ \\
\hline Oil \& gas & 705.21 & 812.37 & 490.18 & 654.34 & 164.16 \\
\hline Basic materials & 446.68 & 504.90 & 310.82 & 193.90 & - \\
\hline Industrials & 439.16 & 505.32 & 234.61 & 241.68 & 7.07 \\
\hline Consumer goods & 58.73 & 67.90 & 40.93 & 293.91 & 252.98 \\
\hline Health care & 41.17 & 47.41 & 27.89 & 167.92 & 140.03 \\
\hline Consumer services & 162.10 & 190.97 & 109.01 & 286.47 & 177.46 \\
\hline Telecommunications & 757.86 & 862.64 & 512.07 & 1268.05 & 755.98 \\
\hline Utilities & 762.41 & 875.33 & 533.68 & 641.55 & 107.87 \\
\hline Technology & 52.62 & 61.04 & 36.72 & 225.38 & 188.66 \\
\hline
\end{tabular}


Thus far, our risk analysis is focused on an absolute risk measure in that it identifies a level of operating cash flow for which we know the probability of that level being exceeded or underperformed. VaR and hence CFaR are two examples of such absolute risk measures.

Another way to think of corporate risk is to calculate a relative risk measure from the distribution of conditional cash flow. Such a measure quantifies the maximum amount by which operating cash flow can fall short of a benchmark, for a desired confidence level, due to the three specific company-level factors used in this study. To calculate this measure, the level of operating cash flow corresponding to a specified level of confidence is subtracted from the specified benchmark, thus yielding the maximum potential shortfall. Although our risk analysis is conducted at the industry and not the company level, this type of relative risk measure may be useful since it conveys information about the likelihood of an outcome relative to a benchmark. In a corporate context, a benchmark level for cash from operations can be estimated by modeling specific activities that generate cash. Alternatively, analyst forecasts could also be used since consensus forecasts condition the market's expectations for corporate performance. Here, we specify the mean of operating cash flows for each industry, as displayed in Table 1 , as the reference level or benchmark ${ }^{9}$.

It is important to note that the calculation of a relative Cash Flow-at-Risk makes sense only for benchmark values greater than the worst case level of operating cash flow for a particular level of confidence. Otherwise, there would be no potential shortfall. The values of CFaR from Table 5 exceed the mean of operating cash flow from Table 1 for the following industries: Oil and gas, Basic Materials, Industrials, and Utilities. Therefore, we recalculate the conditional $\mathrm{CFaR}$ at the $95 \%$ confidence level ${ }^{10}$. At $95 \%$ confidence, a single $\mathrm{CFaR}$ value remains above its benchmark (Basic materials). In general, if the value of the benchmark is too low, the probability of underperformance may or may not be zero, depending on the shape of the distribution of the random variable (operating cash flow in this study) ${ }^{11}$. The relative CFaRs at $95 \%$ confidence are reproduced in the last column of Table 5 .

Relative CFaRs yield somewhat different results in terms of risk classification in comparison with absolute CFaRs. The breakdown of risk groups is clearer than before, but the membership of each group differs significantly. Telecommunications is now the riskiest industry with a relative CFaR equal to USD755 million, which is in line with the previous result. Then, a group of five industries can be identified (Technology, Oil \& Gas, Consumer services, Healt care, and Utilities), with a relative CFaR ranging from USD107 to USD188 million. This group corresponds to the so-called medium-risk class. Within this group, Oil \& Gas and Utilities were classified in the highest risk category according to their absolute CFaR. In contrast, Technology and Healthcare were included in the lowest risk category. Finally, Industrials, which is now the lowest risk industry, was closer to the highest risk group than the lowest.

Such differences between results from absolute and relative CFaR suggest that the choice of a relevant benchmark or operating cash flow threshold is something very important. These two corporate risk measures convey related and complementary information. While absolute $\mathrm{CFaR}$ focuses on the actual levels of operating cash flow, relative $\mathrm{CFaR}$ focuses on specific operating cash flow benchmarks or targets and the corporate-level factors that could lead to missing those targets. Thus, it provides corporate managers with important information about the uncertainty of achieving their goals. While operating cash flow benchmarks could, in theory, be any arbitrary amount, the most useful benchmarks should be the reference levels should typically be reference levels that managers focus on. From a managerial perspective, our results may enable a corporate manager to assess the riskiness of a specific industry or to benchmark its company. Additionally, this kind of risk analysis should be useful in a context of M\&A operations or diversification strategies.

\footnotetext{
${ }^{9}$ In some sense, Expected shortfall may be considered as a relative risk measure since the loss random variable $X$ in [6] will exceed a cut-off value, generally referred to as the $\alpha$-th quantile. We thus focus on a relative CFaR.

${ }^{10}$ Note that there is no particular confidence level that is "best". The particular level used is a company's choice, and depends mostly on how the risk measure will be applied.

${ }^{11}$ Distributions of financial results must not be strongly skewed.
} 


\section{CONCLUSION}

In this paper, we propose a re-characterization of Value-et-Risk (VaR) concepts from a financial environment to a cash flow environment. While non-financial corporations are not required to hold sufficient capital given their risk positions (in contrast with banks), corporate managers know that they may be held liable if the firm is exposed to undue risk through bad risk management practices. "At-Risk" measures such as those used in this study (Cash Flow-at-risk and Expected Shortfall) are feeding off the advances in risk management made by the banking industry, and can be useful in informing a variety of corporate finance decisions.

To our knowledge, this is the first study to assess the general level of riskiness across major U.S. industries by using CFaR. Our investigation reveals significant differences, which gives some confidence that CFaR could be useful to benchmark the overall risk of companies, as compared to the risk of others firms in their respective industries. Transferring the concept underlying VaR to a setting in which cash flows are the targeted variable has received little attention in empirical studies. This neglect should be rectified given our evidence that $\mathrm{CFaR}$ is relevant with respect to corporate risk analysis.

\section{ACKNOWLEDGMENTS}

The author thanks Marie Lebreton from the University of Bordeaux (GREThA - UMR CNRS 5113) for kindly providing her Stata program of the Hsiao's test. For stimulating discussions on a an earlier version of this paper, I would like to thank Eric Bouyé, Head of Strategic Asset Allocation and Quantitative Solutions at the World Bank, Washington D.C.

\section{AUTHOR INFORMATION}

Frantz Maurer is Professor of Finance at KEDGE Business School. He holds a Ph.D. in Management Science and a post-doctoral degree from the University of Bordeaux. His current research interests focus primarily on risk management in the banking industry. Address: KEDGE Business School, 680 cours de la Libération, 33405 Talence cedex (France). Telephone: +33 (0) 556845 573. E-mail: frantz.maurer@kedgebs.com

\section{REFERENCES}

Andrén, N., Jankensgård, H., Oxelheim, L., 2005. Exposure-based Cash-Flow-at-Risk: An alternative to VaR for industrial companies. Journal of Applied Corporate Finance 17, 76-86.

Artzner, P., Delbaen, F., Eber, J-M., Heath, D., 1999. Coherent measures of risk. Mathematical Finance 9, 203-228.

Bartram, S.M., 2007. Corporate cash flow and stock price exposures to foreign exchange rate risk. Journal of Corporate Finance 13, 981-994.

Bartram, S.M., 2008. What lies beneath: Foreign exchange rate exposure, hedging and cash flows. Journal of Banking \& Finance 32, 1508-1521.

Bates, T.W., Kahle, K.M., Stulz, R.M., 2009. Why do U.S. firms hold so much more cash than they used to? Journal of Finance 64, 1985-2021.

Brown, J.R., Petersen, B.C., 2011. Cash holdings and RD smoothing, Journal of Corporate Finance 17, 694-709.

Chay, J.B., Suh, J., 2009. Payout policy and cash-flow uncertainty. Journal of Financial Economics 93, 88-107.

DeMarzo, P., Duffie, D., 1991. Corporate financial hedging with proprietary information. Journal of Economic Theory 53, 261-286.

Froot, K.D., Scharfstein, D., Stein, J., 1993. Risk management: Coordinating investment and financing policies. Journal of Finance 48, 1629-1658.

Greene, W.H., 2008. Econometric Analysis, $6^{\text {th }}$ ed. Prentice Hall, Englewood Cliffs, NJ.

Hausman, J.A., 1978. Specification Tests in Econometrics. Econometrica 46, 1251-1271.

Hsiao, C., 1986. Analysis of Panel Data. Econometric Society Monographs No.11, Cambridge University Press.

Im, K.S., Pesaran, M.H., Shin, Y., 2003. Testing for unit roots in heterogeneous panels. Journal of Econometrics $115,53-74$.

Kwiatkowski, D., Phillips, P.C.B., Schmidt., P., Shin, Y., 1992. Testing the null hypothesis of stationarity against the alternative of a unit root. Journal of Econometrics 54, 159-178. 
Landsman, Z.M., Valdez, E.A., 2003. Tail conditional expectations for elliptical distributions. North American Actuarial Journal 7, 55-71.

Meulbroek, L.K., 2002. A senior manager's guide to integrated risk management. Journal of Applied Corporate Finance 14, 56-70.

Minton, B.A., schrand, C., 1999. The impact of cash flow volatility on discretionary investment and the costs of debt and equity financing. Journal of Financial Economics 54, 423-460.

RiskMetrics, 1999. CorporateMetrics ${ }^{\mathrm{TM}}$ Technical Document, New York: RiskMetrics Group.

Servaes, H., Tamayo, A., Tufano, P., 2009. The theory and practice of corporate risk management. Journal of Applied Corporate Finance 21, 60-78.

Smith, C.W., Stulz, R., 1985. The determinants of firms' hedging policies. Journal of Financial and Quantitative Analysis 18, 391-405.

Stein, J.C., Usher, S.E., LaGattuta, D., Youngen, J., 2001. A comparables approach to measuring cashflow-at-risk for non-financial firms. Journal of Applied Corporate Finance 13, 100-109.

Stock, J.H., Watson, M.W., 2008. Heteroskedasticity-robust standard errors for fixed effects panel data regression. Econometrica 76, 155-174.

Stulz, R., 1996. Rethinking risk management. Journal of Applied Corporate Finance 9, 8-25.

Wooldridge, J.M., 2002. Econometric Analysis of Cross Section and Panel Data. Cambridge, MA: MIT Press. 